\title{
Neurobiological Promises of the Bitter Diterpene Lactone Andrographolide
}

\author{
Rajib Hossain $\left(\mathbb{D},{ }^{1}\right.$ Cristina Quispe, ${ }^{2}$ Jesús Herrera-Bravo $\left(D,{ }^{3,4}\right.$ Jorge F. Beltrán, ${ }^{5}$ \\ Muhammad Torequl Islam $\mathbb{D}^{1}{ }^{1}$ Shabnum Shaheen, ${ }^{6}$ Natália Cruz-Martins $\mathbb{D}^{7,8,9,10}$ \\ Miquel Martorell $\mathbb{D}^{11,12}$ Manoj Kumar ${ }^{1 D},{ }^{13}$ Javad Sharifi-Rad ${ }^{1 D},{ }^{14}$ Fethi Ahmet Ozdemir, ${ }^{15}$ \\ William N. Setzer, ${ }^{16}$ Mohammed M. Alshehri $\mathbb{D}^{17}{ }^{17}$ Daniela Calina $\mathbb{D}^{18}$ \\ and William C. Cho $\mathbb{D D}^{19}$
}

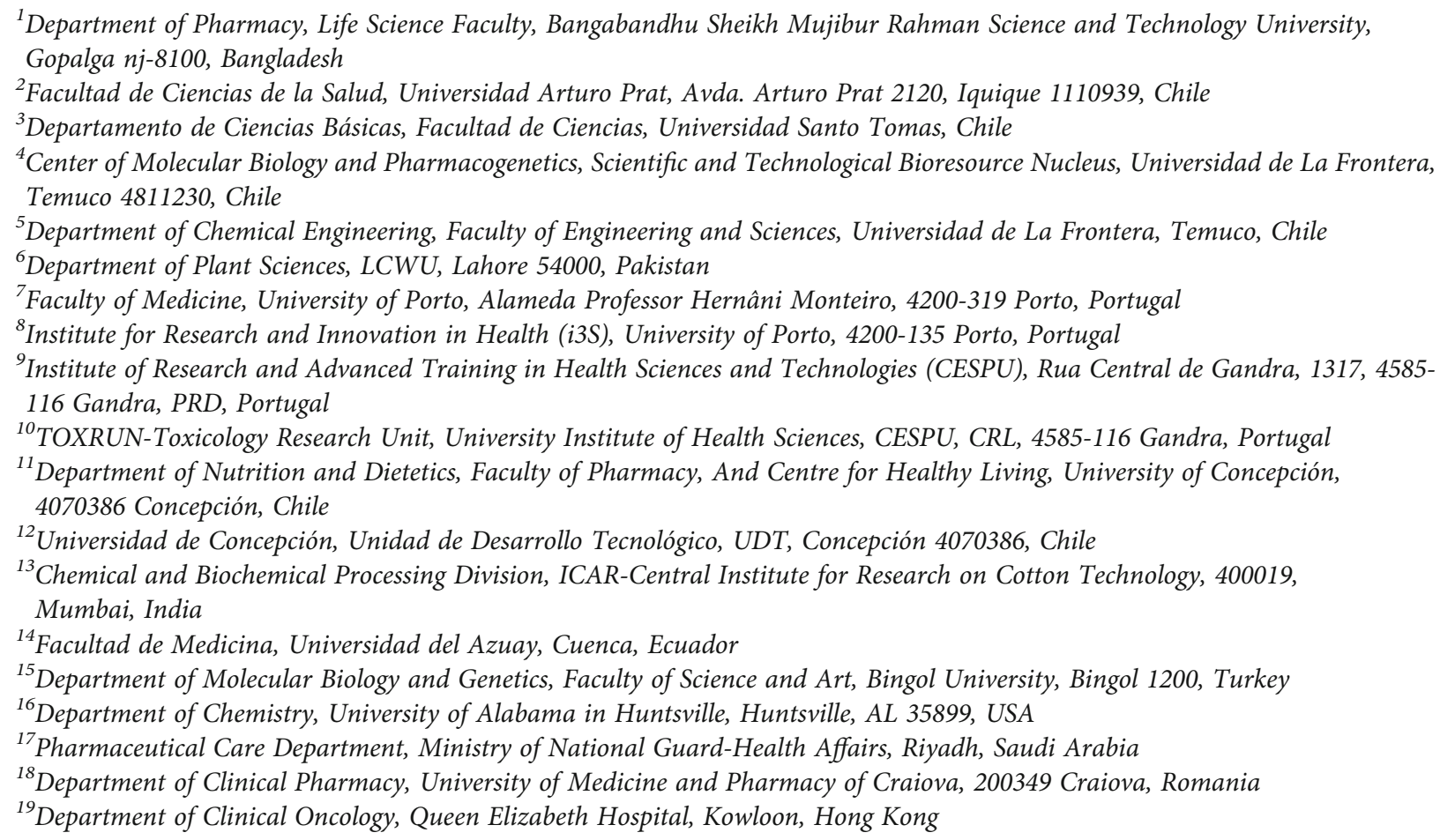

Correspondence should be addressed to Muhammad Torequl Islam; dmt.islam@bsmrstu.edu.bd, Natália Cruz-Martins; ncmartins@med.up.pt, Javad Sharifi-Rad; javad.sharifirad@gmail.com,

Daniela Calina; calinadaniela@gmail.com, and William C. Cho; chocs@ha.org.hk

Received 9 July 2021; Revised 21 November 2021; Accepted 18 January 2022; Published 1 February 2022

Academic Editor: Anderson J. Teodoro

Copyright @ 2022 Rajib Hossain et al. This is an open access article distributed under the Creative Commons Attribution License, which permits unrestricted use, distribution, and reproduction in any medium, provided the original work is properly cited.

Andrographolide (ANDRO), a bitter diterpene lactone found in Andrographis paniculata (Burm.f.) Nees, possesses several biological effects such as antioxidant, anti-inflammatory, and organo-protective effects. Scientific reports suggest that it also has neuroprotective capacity in various test systems. The purpose of this review was to synthesize the neuropharmacological properties of ANDRO and highlight the molecular mechanisms of action that highlight these activities. A careful search was 
done in PubMed and Google Scholar databases using specific keywords. Findings suggest that ANDRO possess neuroprotective, analgesic, and antifatigue effects. Prominent effects were stated on neuro-inflammation, cerebral ischemia, Alzheimer's and Parkinson's diseases, multiple sclerosis, and brain cancer in mice and rats. Furthermore, ANDRO and its derivatives can enhance memory and learning capacity in experimental animals (rats) without causing any toxicity in the brain. Thus, ANDRO may be one of the most promising plant-based psychopharmacological lead compounds for new drug development.

\section{Introduction}

Neurological disorders are very common and important health issues in elderly people $[1,2]$. The inflammation plays a crucial role in several neurodegenerative diseases, including Alzheimer's (AD) disease and Parkinson's (PD), multiple sclerosis (MS), and amyotrophic lateral sclerosis (ALS). Oxidative stress is an important factor in the pathophysiology of many chronic diseases such as diseases of the central system or cancers $[3,4]$. Therefore, much attention has been given to the discovery and development of neurological drugs from various origins $[5,6]$.

Current evidence suggests that plants are a promising source of phytochemicals for the treatment of various diseases [7-9], and thus, phytochemicals are considered one of the most popular tools for sound health maintenance throughout the world [10-13]. Diterpenes are evident in their many promising biological activities, including neuroprotective capacity $[14,15]$.

Andrographolide (ANDRO, $\mathrm{C}_{20} \mathrm{H}_{30} \mathrm{O}_{5}$; Figure 1), a bicyclic diterpene lactone isolated from Andrographis paniculata (Burm.f.) Nees (Family: Acanthaceae), has shown diverse biological activities [15-18].

ANDRO has neurobiological properties, such as antidepressant [19], anti-Alzheimer [20, 21], anti-Parkinsonism [22], neuroprotective [23], antioxidant [24], anticancer [25], and cognitive improvement [26] effects. It also shows neuroprotective effects by inhibiting proinflammatory cytokines such as tumor necrosis factor- $\alpha$ (TNF- $\alpha$ ) and interleukin-1 $\beta$ (IL-1 $\beta$ ) production and microglial activation [27, 28]. In addition, ANDRO $(0.25-8 \mathrm{mg} / \mathrm{kg})$ is known to exert antifatigue activity in experimental animals [29]. Moreover, solid lipid nanoparticles prepared by ANDRO have been found to improve the transport facility through the BBB in healthy rats [30]. No serious toxic effects in mice were observed with two ANDRO derivatives, 3,19-isopropylidenyl- and 3,19-dipalmitoyl, up to $100 \mathrm{mg} / \mathrm{kg}$ [31].

In this sense, the present review is aimed at focusing on ANDRO neurobiological effects.

\section{Search Strategy}

A search was done in the following databases: PubMed/ Medline and Google Scholar using the next MeSH terms: "Diterpenes", "Neuroprotective Agents", "Andrographolide", "Animals", "Central Nervous System/drug effects", "Diterpenes/pharmacology", "Diterpenes/therapeutic use", "Humans", "Neuroprotective Agents/pharmacology", and "Neuroprotective Agents/therapeutic use".

The research was done according to the consensus statement of researchers active in ethnopharmacology and with particular input by the ConSEFS Advisory group [32], and the name of the plant was verified according to the PlantList [33]. No language restrictions were imposed, and manuscripts were evaluated for dose/concentration, administration route, test systems, results, discussion, conclusion, and proposed mechanisms of action.

The following inclusion criteria were considered:

(1) Studies developed in vitro, ex vivo, or in vivo, and humans and their derived tissues and cells

(2) Studies with ANDRO and its derivatives

(3) ANDRO or its derivative joint effects with other chemical compounds

(4) Studies with or without proposing mechanisms of action

After careful search and strict analysis, 38 reports (PubMed: 28; Google Scholar: 10) were included. The most important mechanism of ANDRO' effects on $\mathrm{AD}, \mathrm{PD}, \mathrm{MS}$, cerebral ischemia, intracerebral haemorrhage, neuropathic pain, brain tumour, and depression is summarized in Table 1 and Figure 2.

\section{The Neurobiological Role of Andrographolide: Molecular Mechanisms and Pathways}

3.1. Andrographolide and Neurodegenerative Diseases. Neurodegeneration occurs in the CNS and involves the loss of neuronal structure and function, triggered by several factors including CNS inflammation [34, 35]. CNS degeneration involves the progressive chronic loss of neural structure and function, resulting in functional and mental neurological deficiencies $[7,13]$.

3.1.1. Alzheimer's Disease. Alzheimer's disease (AD) is a chronic neurodegenerative disease, which usually has a slow progression and gradually worsens over time. It is the cause of $60-70 \%$ of cases of dementia $[36,37]$.

Current treatment protocols are not sufficient for effectively preventing AD signs and symptoms [38, 39]. Many natural resources have been discovered in recent decades which can be used as adjuvant therapies in the treatment of $\mathrm{AD}$. [8, 40, 41].

In some recent studies, ANDRO administration (2 and $4 \mathrm{mg} / \mathrm{kg}$ i.p.) suppressed the spatial learning and memory function impairment in Octodon degus [42], and the proposed mechanisms of ANDRO were as follows: (1) recovery of learning performance and spatial memory, (2) synaptic basal transmission recovery, (3) protection of synaptic 
proteins, and (4) lowering of amyloid-beta $(\mathrm{A} \beta)$ aggregate maturation and phosphorylated tau protein [42].

In another study, ANDRO $(2 \mathrm{mg} / \mathrm{kg})$ was found to improve learning/memory by activating Wnt signaling. Wnt is a signaling pathway that enhances glucose metabolism via gene expression and/or activity enhancement of hexokinase, phosphofructokinase, and AMP-activated protein kinase (AMPK) [20, 43].

ANDRO also reduced the $\mathrm{A} \beta$ levels and tau phosphorylation and changed amyloid plaques in A $\beta$ PPswe/PS- 1 double transgenic male mice [26]. Hence, ANDRO recovered synaptic proteins, increases $\beta$-catenin levels, reduces active glycogen synthase kinase- (GSK-) $3 \beta$ levels, increases synaptic transmission, and protects long-term potentiation (LTP) at the same time that suppresses postsynaptic-densityprotein 95 (PSD-95), GluA2, GluN2B, and Shank decrease in the hippocampus [26]. Besides, the activation of nuclear factor erythroid 2-related factor 2- (Nrf2-) mediated heme oxygenase (HO)-1 expression, ANDRO (1-10 $\mu \mathrm{M})$ also inhibited A $\beta 42$-overexpression in microglial BV-2 cells [44].

In human microglia cells, ANDRO also inhibited nuclear factor- (NF-) $\kappa \mathrm{B}$ translocation via $\mathrm{I} \kappa \mathrm{B}$ phosphorylation modulation and attenuated $A \beta-$ (1-42-) induced Jun $N$ terminal kinase- (JNK-) mitogen-activated protein kinase (MAPK) overactivation [45]. ANDRO sulfonate (2.5 and $5 \mathrm{mg} / \mathrm{kg}, 5$ months) was found to inhibit AD via mitochondria protection in APPswe/PSEN $\Delta 9$ double transgenic mice having $\mathrm{AD}[46]$.

Other studies narrate that ANDRO treatment during chronic cerebral hypoperfusion suppressed astrocyte activation supported by decreased expression of the glial fibrillary acid protein (GFAP), enhanced brain-derived neurotrophic factor (BDNF) and tyrosine kinase receptor $\mathrm{B}(\operatorname{TrkB})$ expression, and reversed upregulated expression of TNF- $\alpha$, IL- $1 \beta$, and caspase- 3 . Thus, in the rat model of chronic cerebral hypoperfusion, ANDRO improved impaired spatial learning and memory [47].

3.1.2. Parkinson Disease. Parkinson's disease (PD) is described as a gradual loss of midbrain substantia nigra dopaminergic neurons [48, 49].

Some researchers have shown that pretreatment with ANDRO (0.5-5 $\mu \mathrm{M})$ abolished lipopolysaccharide- (LPS-) induced decrease in dopamine (DA) uptake but failed to affect 1-methyl-4-phenyl-pyridine- (MPP-) induced decrease in DA uptake. Thereby, ANDRO (1-5 M) reduced the tyrosine hydroxylase- ( $\mathrm{TH}-)$ immunoreactive neuron loss and shortened TH-immunoreactive dendrites [22]. Microglia-derived toxic factors include proinflammatory mediators such as reactive oxygen species (ROS), prostaglandin E2 (PGE2), TNF- $\alpha$, inducible nitric oxide synthetase (iNOS), nitric oxide (NO), and cyclooxygenase 2 (COX2) $[50,51]$.

Anxiety and depressive disorders are frequently comorbid with PD [52]. Thus, a forced swimming test was performed in mice to measure depressive symptoms. After ANDRO $(5 \mathrm{mg} / \mathrm{kg})$ treatment, the swimming time was noticeably enhanced showing an improvement of depressive symptoms [53]. Geng et al. [54] provided evidence that

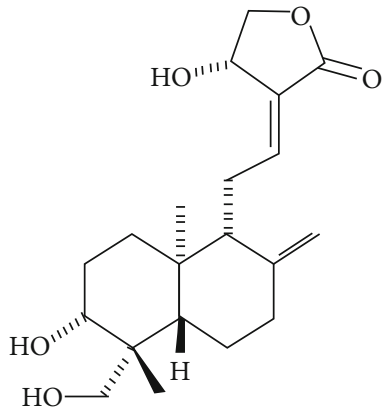

Figure 1: Andrographolide chemical structure.

ANDRO attenuated DA neuron loss, oxidative stress, and preserved mitochondrial morphology and also reduced mitochondrial malfunctions, reduced cell death, and inhibited GTPase activity in 1-methyl-4-phenyl-1,2,3,6-tetrahydropyridine- (MPTP-) induced PD. Apoptosis is also an important factor that triggers PD.

ANDRO reduced $\mathrm{Ca}^{2+}$ influx [55], intracellular ROS production [56], and lipid peroxidation. In addition, ANDRO regulated Bcl-2, Bid, Bax, and apoptosis-inducing factor levels. ANDRO also inhibited the phosphorylation of mitogen-activated protein kinases (p38, extracellular signal-regulated kinase (ERK), and $c$-JNK) [55].

ANDRO $(0.1-10 \mu \mathrm{M})$ was found to decrease apoptosis and inhibited IL-2 [57] and maybe an antagonist of phorbol-12-myristate-13-acetate (PMA) which stimulated remarkable ROS production [56].

3.1.3. Multiple Sclerosis. Multiple sclerosis (MS) is a wellknown immune-mediated disorder, in which insulating covers of nerve cells in the spinal cord and brain are damaged in the CNS [58]. From the MS pathogenesis, it was found that $\mathrm{CD}^{+}{ }^{+} \mathrm{T}$-cell-mediated autoimmunity is crucial in MS pathogenesis, mainly for early disease initiation [59, 60]. T-helper type 1 (Th1) cells, characterized by interferon(IFN-) $\gamma$ production, mediate the MS pathogenesis $[61,62]$, but IL-17-expressing T-helper cells (Th17) are also involved. $\mathrm{CD}^{+}$, as well as $\mathrm{CD} 4^{+} \mathrm{T}$ cells, was equally immune-stained for IL-17 and IL-17 production inactive areas of MS lesions [63].

ANDRO inhibits the dendritic cells ability and generates peptide-major histocompatibility complexes required for $\mathrm{T}$ cell activation. In LPS-treated dendritic cells, ANDRO attenuated the upregulation of the maturation markers $\mathrm{I}_{-} \mathrm{A}^{\mathrm{b}}$, CD40, and CD86 (B7.2) [16]. Besides, ANDRO also suppressed $\mathrm{T}$ cell function, IFN- $\gamma$, and IL-2 production [57]. These effects may contribute to ANDRO's therapeutic potential, ameliorating MS symptoms in autoimmune encephalomyelitis mice through inhibition of T-cell activation and antibody responses directed to the myelin sheath [16].

\subsection{Andrographolide and Stroke}

3.2.1. Ischemic Stroke. Cerebral ischemia occurs when the metabolic demand of brain is not satisfied due to an insufficient blood flow $[48,64]$. This involves cerebral hypoxia 
TABLE 1: ANDRO neuropharmacological activities and possible mechanism of action.

\begin{tabular}{|c|c|c|}
\hline Neurological/psychiatric disorders & Results/possible mechanisms & References \\
\hline Alzheimer disease & $\begin{array}{c}\text { Neuroprotective } \\
\downarrow \text { A } \beta \text { protein } \\
\downarrow \text { Caspase-3 expression } \\
\downarrow \text { Apoptosis } \\
\downarrow \text { Neuronal cell death }\end{array}$ & ([20], [44], [47], [26], [46]) \\
\hline Parkinson's disease & $\begin{array}{c}\text { Neuroprotective } \\
\downarrow \text { ROS, } \downarrow \text { NO } \\
\downarrow \text { TNF- } \alpha \\
\downarrow \text { IL-1 } \beta \\
\downarrow \text { Lipid peroxidation } \\
\downarrow \text { Apoptosis } \\
\downarrow \text { Cell death }\end{array}$ & ([22], [94], [95], [52], [50], [51], [55], [56], [57], [54]) \\
\hline Multiple sclerosis & $\begin{array}{c}\text { Neuroprotective } \\
\downarrow \text { T-cell activation } \\
\downarrow \text { IFN- } \gamma \\
\downarrow \text { TNF- } \alpha \\
\downarrow \text { IL- } 1 \beta, \downarrow \text { IL-2 } \\
\downarrow \text { Apoptosis }\end{array}$ & $([16],[62],[61],[63],[57],[96])$ \\
\hline Cerebral ischemia & $\begin{array}{c}\text { Neuroprotective } \\
\downarrow \beta \text {-Catenin } \\
\downarrow \text { Caspase-3 } \\
\downarrow \text { NF- } \kappa \mathrm{B} \\
\downarrow \text { Apoptosis } \\
\downarrow \text { Neuroinflammation }\end{array}$ & $([24],[27],[68],[69],[97],[70])$ \\
\hline Intracerebral hemorrhage & $\begin{array}{c}\downarrow \text { Brain injury } \\
\downarrow \text { Catenin-1 } \\
\downarrow \text { TNF- } \alpha \\
\downarrow \text { IL- } 1 \beta \\
\downarrow \text { IL-6 }\end{array}$ & $([15],[23],[98],[71],[72])$ \\
\hline Neuropathic pain & $\begin{array}{c}\downarrow \text { TNF- } \alpha \\
\downarrow \text { IL-1 } \beta \\
\downarrow \text { Neuronal excitability } \\
\downarrow \text { Central and peripheral pain sensitization }\end{array}$ & $([31],[75],[76],[77])$ \\
\hline Brain tumor & $\begin{array}{c}\uparrow \mathrm{p} 53 \text { and ERK phosphorylation } \\
\uparrow \text { Caspase-7 } \\
\uparrow \text { Apoptosis }\end{array}$ & $([83],[81],[82],[84])$ \\
\hline Depression & $\begin{array}{c}\downarrow \text { Inflammation } \\
\downarrow \text { NO, } \downarrow \text { iNOS } \\
\downarrow \text { COX-2 } \\
\downarrow \text { TNF- } \alpha \\
\downarrow \text { IL- } 1 \beta, \downarrow \text { IL-6 } \\
\uparrow \beta \text {-Catenin } \\
\uparrow \text { BDNF } \\
\uparrow \text { pSer9 }\end{array}$ & ([19], [93], [92], [54], [90], [91], [89]) \\
\hline
\end{tabular}

$\uparrow$ : increase; $\downarrow$ : decrease; A $\beta$ : amyloid beta; COX-2: cyclooxygenase 2; ERK: extracellular signal-regulated kinase; IFN: interferon; IL: interleukin; NF- $\kappa$ B: nuclear factor $\kappa \mathrm{B}$; NO: nitric oxide; ROS: reactive oxygen species.

leading to the death of brain tissues $[65,66]$. Cerebral ischemia is one of the serious causes of morbimortality worldwide. The treatment options against cerebral ischemia/ stroke are limited [67].

Some studies have shown that ANDRO (0.1 and $1 \mathrm{mg} / \mathrm{kg}$ i.p) lowered the infarct volume and neurological deficits and drastically reduced microglia cells in permanent middle cerebral artery occlusion- (pMCAO-) induced rat model [27]. On the other hand, ANDRO showed a neuroprotective effect by reducing inflammation in the MCAO-induced rat model. ANDRO abolished neuroinflammatory markers, such as IL- $1 \beta$ and TNF- $\alpha$. ANDRO also suppressed NF- $\kappa \mathrm{B}$ activation [27].

Another study showed that ROS production and protein nitrosylation, iNOS, gp91phox/NADPH oxidase 2 (NOX2), IL- $1 \beta$, and HIF- $1 \alpha$ levels were decreased by ANDRO ( 5 and $10 \mu \mathrm{g} / \mathrm{kg}$, i.v.) in cerebral ischemia in rats [68]. Furthermore, NOX2 and iNOS expression were reduced by impairing $\mathrm{PI} 3 \mathrm{~K} /$ protein kinase B- (AKT-) dependent NF- $\kappa \mathrm{B}$ and HIF-1 $\alpha$ activation in cerebral ischemia in mice [24]. 

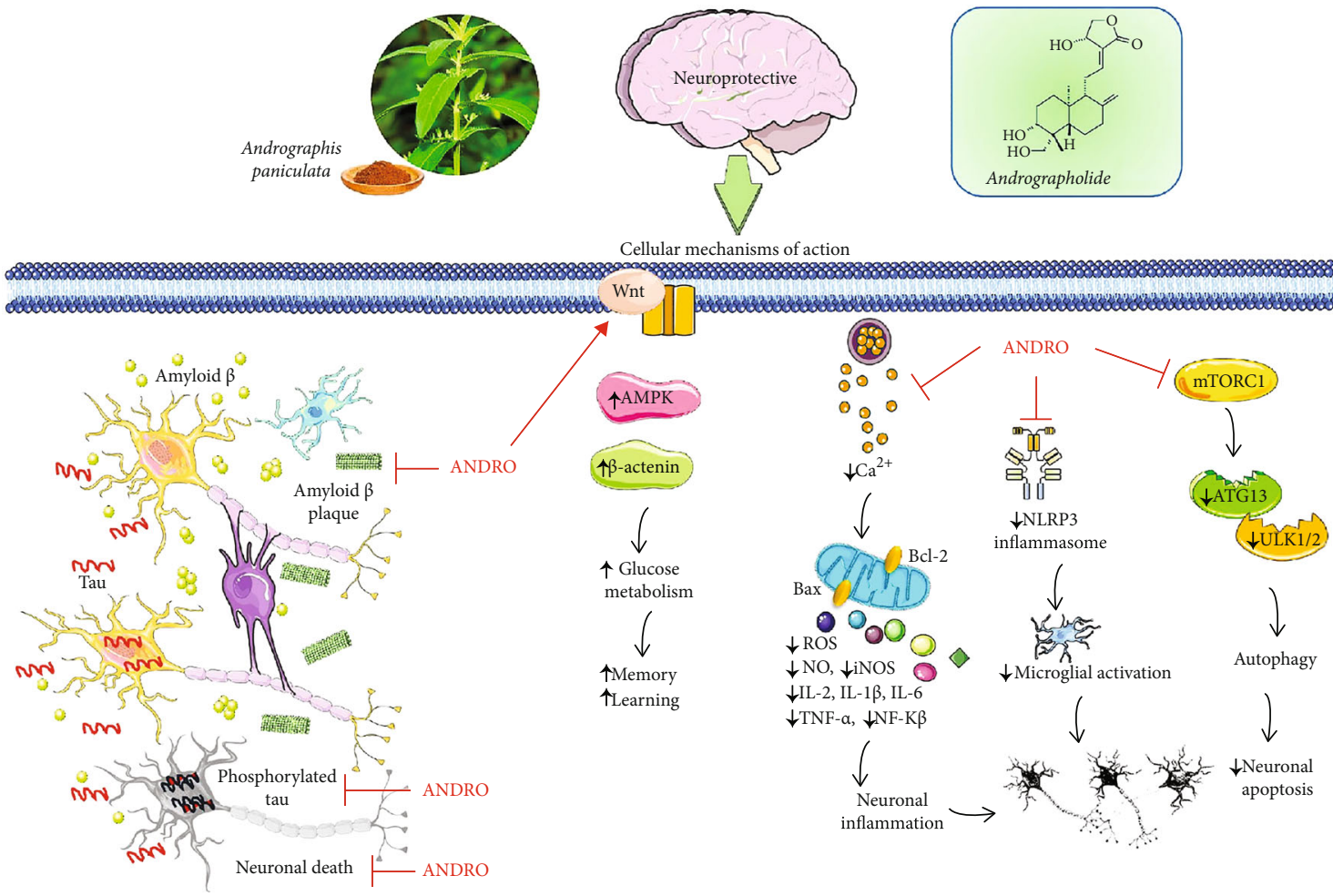

FIGURE 2: Schematic representation of the most important molecular mechanisms and signaling pathways of andrographolide in central nervous system disorders. $\uparrow$ : increase; $\downarrow$ : decrease; ANDRO: andrographolide; ROS: reactive oxidative species; NO: nitric oxide; iNOS: inducible nitric oxide; IL: interleukins; TNF: tumor necrosis alpha; NF- $\kappa$ B: nuclear factor kappa-light-chain-enhancer of activated B cells. ATG 13 autophagy-related protein 13, ULK $1 \frac{1}{2}$ Unc-51 like autophagy activating kinase.

ANDRO, in rat hippocampal cultures, also inhibited GSK$3 \beta$ in a non-ATP-competitive, substrate-competitive way [69].

In a recent study, ANDRO (5-100 $\mu \mathrm{g} / \mathrm{kg}$, i.p.) increased $\mathrm{Wnt} / \beta$-catenin signaling as evidenced by the enhanced nuclear $\beta$-catenin expression and inhibited GSK-3 $\beta$ (pSer9) [70].

3.2.2. Hemorrhagic Stroke. Intracerebral hemorrhage (ICH) occurs within brain tissue or ventricles [71] and is a prime CNS health problem all over the world with high morbimortality rates. So far, no effective strategies exist to treat this disorder, and nearly $20 \%$ of patients achieve therapeutic outcomes [72]. There are several causes of, including neuroinflammation and microglial activation. Therefore, prevention and secondary treatment of brain injury are important for patients with ICH $[23,73]$.

In some studies, ANDRO ( 1 and $2 \mathrm{mg} / \mathrm{kg}$ ) was able to reduce neurobehavioral damage, the water content in the brain, alleviate neuronal cell death, and degeneration in ICH-induced SBI rats [23]. Further experimental analysis shows that ANDRO has inhibitory effects on CD11b + and CD16+ microglia cells and attenuated TNF- $\alpha$ and IL- 6 level by deactivating the NF- $\kappa \mathrm{B}$ signaling pathway through reverse phosphorylation of $\mathrm{I} \kappa \mathrm{B} \alpha$ and $\mathrm{p} 65$ in ICH rats [23]. Furthermore, in the ICH brain, ANDRO reduced caspase1-caspase-recruitment domain (ASC) and NLRP3-ASC interaction, thereby inhibiting caspase-1/gasdermin D cleavage and IL-1 $\beta$ production [23]. In addition, ANDRO sup- presses NF- $\kappa \mathrm{B}$ and NLPR3 inflammasome activation via p65 translocation assembly inhibition of NLRP3/ASC/caspase-1 complex [23] and can reduce SBI after ICH [15].

3.3. Andrographolide and Neuropathic Pain. Pain sensation occurs when tissue injury is detected by nociceptors [74]. ANDRO $(25,50,100 \mathrm{mg} / \mathrm{kg})$ is evident to exert analgesic effects by reducing writhing reflex [75]. ANDRO and its derivatives 14-deoxy-11,12-didehydroandrographolide, 14acetyl-3,19-isopropylidenyl-, and 3,19-dipalmitoyl-derivatives $(4 \mathrm{mg} / \mathrm{kg})$ exerted analgesic effects in hot plate and writhing test in mice [31].

ANDRO is also evident to exert analgesic effects in Charles Foster male albino rats [76]. ANDRO (25 mg/ $20 \mathrm{~mL}$ ) also attenuated mechanical and thermal hyperalgesia and downregulated the expression of the P2X7 receptor. Besides this, ANDRO decreased TNF- $\alpha$ and IL- $1 \beta$ expression, increased IL-10 expression, inhibited ERK signaling pathways activation, and also decreased the coexpression of GFAP and P2X7 receptors [77], thus reducing neuropathic pain in the HIV rat model.

3.4. Andrographolide and Brain Tumors. Glioma is a tumor occurring in the glial cells of the brain or spine [78] and comprises about $30 \%$ of all brain tumors and $80 \%$ of all malignant brain tumors in CNS [79]. Targeted therapies for cancer are a rapidly advancing field for treating tumor, and natural products have become the best choice for researchers ([80], Sharifi-Rad et al., 2021b). 
ANDRO showed anticancer potential in several cancer cell types $[25,81]$. ANDRO $(15 \mu M)$ induced cell death of glioblastoma (C6) cells by inducing apoptosis through ROS-extracellular receptor kinase- (ERK-) p53-caspase 7and PARP-pathways in mouse glioblastoma (C6) cells. ANDRO could increase apoptosis through both phosphorylations of p53 and p53 activation. Because ANDRO increased p53 levels in neural cells [55], findings suggest that ANDRO can promote $\mathrm{p} 53$ protein activation, which activates the downstream caspase 7-PARP cascade [82] and is regulated by ERK [83]. In a recent study, ANDRO accelerated RSC96 cell proliferation [84].

3.5. Andrographolide and Depression. One of the most common neuropsychiatric disorders in the world is depression [85-87]. Characterized by a variety of signs and symptoms, antidepressants have been increasingly used for depression treatment in daily life, but their multiple side effects and high rates of failure have triggered the researchers' interest to find more effective and safer therapeutic strategies [88]. ANDRO $(5 \mathrm{mg} / \mathrm{kg})$ administration can improve depressivelike behaviour, as well as to attenuate the expression of proinflammatory mediators and cytokines, including NO, iNOS, COX-2, IL- $1 \beta$, IL- 6 and TNF- $\alpha$, NF- $\kappa$ B signaling (p$\mathrm{p} 65, \mathrm{p}-\mathrm{I} \kappa \mathrm{B} \alpha$ ), and NLRP3 inflammasome assembly (NLRP3, ASC, and caspase-1) in the prefrontal cortex. Besides, ANDRO $(5 \mathrm{mg} / \mathrm{kg})$ increased Beclin1 expression and abrogated phosphorylated mTORC1 (p-mTOR), revealing autophagic activity in the prefrontal cortex of chronic unpredictable mild stress mice [54]. Beclin1 stimulates the initial stages of autophagy, and p-mTOR inhibits autophagy through ATG13 and ULK1/2 phosphorylation [89]. ANDRO-generated autophagy can attenuate depressive-like symptoms, inhibits inflammation, and shows antidepressive effects [54].

In another study performed in mice, ANDRO (20 and $50 \mathrm{mg} / \mathrm{kg}$ ) activated hippocampal BDNF system, thus showing antidepressant effects $[19,90]$. Also, ANDRO inhibited the long-term depression in a concentration-dependent way, showing $\beta$-catenin accumulation and reducing the GSK-3 $\beta$ active state [91-93].

\section{Conclusions}

The antioxidant and anti-inflammatory effects of ANDRO and some of its derivatives are well-known. It is also widely recognized that substances with these kinds of properties are cytoprotective and can protect animal organs. This review gives insights on the neuro-pharmacological effects of ANDRO and its derivatives in several test systems. In light of these data, ANDRO can be considered one of the most important neuro-protective phytochemicals that can be considered as an adjuvant treatment in neurodegenerative diseases such as AD, PD, and MS. Further studies are needed to find solutions such as nanocarriers, to increase the bioavailability of ANDRO in order to cross the blood-brain barrier by incorporating in pharmaceutical formulations such as nanoparticles.

\section{Data Availability}

The data used to support the findings of this study are available from the corresponding author upon request.

\section{Conflicts of Interest}

The authors declare no conflict of interest.

\section{Authors' Contributions}

All authors made a significant contribution to the work reported, whether that is in the conception, study design, execution, acquisition of data, analysis, interpretation, or in all these areas that is revising or critically reviewing the article, giving final approval of the version to be published, agreeing on the journal to which the article has been submitted, and confirming to be accountable for all aspects of the work.

\section{Acknowledgments}

This work was supported by the CONICYT PIA/APOYO CCTE AFB170007.

\section{References}

[1] S. F. Nabavi, S. Tejada, W. N. Setzer et al., "Chlorogenic acid and mental diseases: from chemistry to medicine," Current Neuropharmacology, vol. 15, no. 4, pp. 471-479, 2017.

[2] B. Salehi, D. Calina, A. O. Docea et al., "Curcumin's nanomedicine formulations for therapeutic application in neurological diseases," Journal of Clinical Medicine, vol. 9, no. 2, p. 430, 2020.

[3] A. Reynolds, C. Laurie, R. L. Mosley, and H. E. Gendelman, "Oxidative stress and the pathogenesis of neurodegenerative disorders," International Review of Neurobiology, vol. 82, pp. 297-325, 2007.

[4] D. Tsoukalas, P. Fragkiadaki, A. O. Docea et al., "Association of nutraceutical supplements with longer telomere length," International Journal of Molecular Medicine, vol. 44, no. 1, pp. 218-226, 2019.

[5] B. Salehi, S. Sestito, S. Rapposelli et al., "Epibatidine: a promising natural alkaloid in health," Biomolecules, vol. 9, no. 1, p. 6, 2019.

[6] B. Salehi, M. Shivaprasad Shetty, N. V Anil Kumar et al., "Veronica plants-drifting from farm to traditional healing, food application, and phytopharmacology," Molecules, vol. 24, no. 13, p. 2454, 2019.

[7] L. A. Nussbaum, L. M. Hogea, D. A. Călina et al., "Modern treatment approaches in psychoses. Pharmacogenetic, neuroimagistic and clinical implications," Farmacia, vol. 65, pp. 7581, 2017.

[8] T. A. Sani, E. Mohammadpour, A. Mohammadi et al., "Cytotoxic and apoptogenic properties of Dracocephalum kotschyi aerial part different fractions on CALU-6 and MEHR-80 lung cancer cell lines," Farmácia, vol. 65, pp. 189-199, 2017.

[9] D. Tsoukalas, P. Fragkiadaki, A. O. Docea et al., "Discovery of potent telomerase activators: unfolding new therapeutic and anti-aging perspectives," Molecular Medicine Reports, vol. 20, no. 4, pp. 3701-3708, 2019. 
[10] B. Salehi, D. A. Konovalov, P. Fru et al., "Areca catechu-from farm to food and biomedical applications," Phytotherapy Research, vol. 34, no. 9, pp. 2140-2158, 2020.

[11] B. Salehi, Z. Selamoglu, B. Sener et al., "Berberis plants-drifting from farm to food applications, phytotherapy, and phytopharmacology," Food, vol. 8, no. 10, p. 522, 2019.

[12] J. Sharifi-Rad, A. Bahukhandi, P. Dhyani et al., "Therapeutic potential of neoechinulins and their derivatives: an overview of the molecular mechanisms behind pharmacological activities," Frontiers in Nutrition, vol. 8, article 664197, 2021.

[13] J. Sharifi-Rad, S. Kamiloglu, B. Yeskaliyeva et al., "Pharmacological activities of psoralidin: a comprehensive review of the molecular mechanisms of action," Frontiers in Pharmacology, vol. 11, p. 11, 2020

[14] M. T. Islam, C. B. da Silva, M. V. O. B. de Alencar, M. F. C. J. Paz, F. R. . C. Almeida, and A. A. . C. Melo-Cavalcante, "Diterpenes: advances in neurobiological drug research," Phytotherapy Research, vol. 30, no. 6, pp. 915-928, 2016.

[15] J. Lu, Y. Ma, J. Wu et al., "A review for the neuroprotective effects of andrographolide in the central nervous system," Biomedicine \& Pharmacotherapy, vol. 117, 2019.

[16] M. I. Iruretagoyena, J. A. Tobar, P. A. González et al., “Andrographolide interferes with $\mathrm{T}$ cell activation and reduces experimental autoimmune encephalomyelitis in the mouse," The Journal of Pharmacology and Experimental Therapeutics, vol. 312, no. 1, pp. 366-372, 2005.

[17] S. K. Mishra, N. S. Sangwan, and R. S. Sangwan, “Andrographis paniculata (Kalmegh): a review," Pharmacognosy Reviews, vol. 1, no. 2, pp. 283-298, 2007.

[18] E. J. Seo, S. M. Klauck, T. Efferth, and A. Panossian, “Adaptogens in chemobrain (part I): plant extracts attenuate cancer chemotherapy-induced cognitive impairment transcriptome-wide microarray profiles of neuroglia cells," Phytomedicine, vol. 55, pp. 80-91, 2019.

[19] J. J. Zhang, T. T. Gao, Y. Wang et al., "Andrographolide exerts significant antidepressant-like effects involving the hippocampal BDNF system in mice," The International Journal of Neuropsychopharmacology, vol. 22, no. 9, pp. 585-600, 2019.

[20] P. Cisternas, J. M. Zolezzi, M. Martinez, V. I. Torres, G. W. Wong, and N. C. Inestrosa, "Wnt-induced activation of glucose metabolism mediates the in vivo neuroprotective roles of Wnt signaling in Alzheimer disease," Journal of Neurochemistry, vol. 149, no. 1, pp. 54-72, 2019.

[21] C. B. Lindsay, J. M. Zolezzi, D. S. Rivera, P. Cisternas, F. Bozinovic, and N. C. Inestrosa, "Andrographolide reduces neuroinflammation and oxidative stress in aged Octodon degus," Molecular Neurobiology, vol. 57, no. 2, pp. 11311145, 2020.

[22] T. Wang, B. Liu, W. Zhang, B. Wilson, and J. S. Hong, “Andrographolide reduces inflammation-mediated dopaminergic neurodegeneration in mesencephalic neuron-glia cultures by inhibiting microglial activation," The Journal of Pharmacology and Experimental Therapeutics, vol. 308, no. 3, pp. 975-983, 2004.

[23] X. Li, T. Wang, D. Zhang et al., “Andrographolide ameliorates intracerebral hemorrhage induced secondary brain injury by inhibiting neuroinflammation induction," Neuropharmacology, vol. 141, pp. 305-315, 2018.

[24] C.-M. Chern, K.-T. Liou, Y.-H. Wang, J.-F. Liao, J.-C. Yen, and Y.-C. Shen, "Andrographolide inhibits PI3K/AKT-dependent
NOX2 and iNOS expression protecting mice against hypoxia/ischemia-induced oxidative brain injury," Planta Medica, vol. 77, no. 15, pp. 1669-1679, 2011.

[25] S. K. Mishra, S. Tripathi, A. Shukla, S. H. Oh, and H. M. Kim, "Andrographolide and analogues in cancer prevention," Frontiers in Bioscience (Elite Edition), vol. 7, no. 2, pp. 255-266, 2015.

[26] F. G. Serrano, C. Tapia-Rojas, F. J. Carvajal, J. Hancke, and W. Cerpa, "Andrographolide reduces cognitive impairment in young and mature A $\beta$ PPswe/PS-1 mice," Molecular Neurodegeneration, vol. 9, no. 1, p. 61, 2014.

[27] S. J. Chan, W. S. F. Wong, P. T. H. Wong, and J.-S. Bian, "Neuroprotective effects of andrographolide in a rat model of permanent cerebral ischaemia," British Journal of Pharmacology, vol. 161, no. 3, pp. 668-679, 2010.

[28] M.-Y. Yang, Q.-L. Yu, Y.-S. Huang, and G. Yang, "Neuroprotective effects of andrographolide derivative CX-10 in transient focal ischemia in rat: involvement of Nrf2/AE and TLR/NF- $\kappa \mathrm{B}$ signaling," Pharmacological Research, vol. 144, pp. 227-234, 2019.

[29] S. ASAMIO, K. SAITO, A. MAEDA, and N. TATEISHI, “Antifatigue agents and oral compositions containing andrographolide as active ingredient," 2013, US-8507547-B2.

[30] G. Graverini, V. Piazzini, E. Landucci et al., "Solid lipid nanoparticles for delivery of andrographolide across the bloodbrain barrier: in vitro and in vivo evaluation," Colloids and Surfaces. B, Biointerfaces, vol. 161, pp. 302-313, 2018.

[31] S. Suebsasana, P. Pongnaratorn, J. Sattayasai, T. Arkaravichien, S. Tiamkao, and C. Aromdee, "Analgesic, antipyretic, anti-inflammatory and toxic effects of andrographolide derivatives in experimental animals," Archives of Pharmacal Research, vol. 32, no. 9, pp. 1191-1200, 2009.

[32] M. Heinrich, G. Appendino, T. Efferth et al., "Best practice in research - overcoming common challenges in phytopharmacological research," Journal of Ethnopharmacology, vol. 246, article 112230, 2020.

[33] T. Plantlist, 2021, http://www.theplantlist.org/.

[34] W. E. I.-W. E. I. CHEN, X. I. A. ZHANG, and W. E. N.-J. U. A. N. HUANG, "Role of neuroinflammation in neurodegenerative diseases (review)," Molecular Medicine Reports, vol. 13, no. 4, pp. 3391-3396, 2016.

[35] B. Salehi, A. Prakash Mishra, M. Nigam et al., "Ficus plants: state of the art from a phytochemical, pharmacological, and toxicological perspective," Phytotherapy Research, vol. 35, no. 3, pp. 1187-1217, 2021.

[36] ALZHEIMER'S DISEASE INTERNATIONAL, Worl Alheimer Report 2019, Alzheimer's Disease International, Attitudes to dementia, London, 2019.

[37] J. A. Hardy and G. A. Higgins, “Alzheimer's disease: the amyloid cascade hypothesis,” Science, vol. 256, no. 5054, pp. 184$185,1992$.

[38] A. O. Docea, D. Calina, A. M. Buga et al., "The effect of silver nanoparticles on antioxidant/pro-oxidant balance in a murine model," International Journal of Molecular Sciences, vol. 21, no. 4, p. 1233, 2020.

[39] J. Janoutová, O. Šerý, L. Hosák, and V. Janout, "Is mild cognitive impairment a precursor of Alzheimer's disease? Short review," Central European Journal of Public Health, vol. 23, no. 4, pp. 365-367, 2015.

[40] M. S. Islam, C. Quispe, R. Hossain et al., "Neuropharmacological effects of quercetin: a literature-based review," Frontiers in Pharmacology, vol. 12, 2021. 
[41] B. Salehi, A. Rescigno, T. Dettori et al., "Avocado-soybean unsaponifiables: a panoply of potentialities to be exploited," Biomolecules, vol. 10, no. 1, p. 130, 2020.

[42] D. S. Rivera, C. Lindsay, J. F. Codocedo et al., "Andrographolide recovers cognitive impairment in a natural model of Alzheimer's disease (Octodon degus)," Neurobiology of Aging, vol. 46, pp. 204-220, 2016.

[43] N. C. Inestrosa, C. Tapia-Rojas, C. B. Lindsay, and J. M. Zolezzi, "Wnt signaling pathway dysregulation in the aging brain: lessons from the Octodon degus," Frontiers in Cell and Development Biology, vol. 8, p. 734, 2020.

[44] J. Y. Seo, E. Pyo, J. P. An, J. Kim, S. H. Sung, and W. K. Oh, "Andrographolide activates Keap1/Nrf2/ARE/HO-1 pathway in HT22 cells and suppresses microglial activation by $\mathrm{A} \beta(42)$ through Nrf2-related inflammatory response," Mediators of Inflammation, vol. 2017, Article ID 5906189, 12 pages, 2017.

[45] C. H. Yang, T. L. Yen, C. Y. Hsu, P. A. Thomas, J. R. Sheu, and T. Jayakumar, "Multi-targeting andrographolide, a novel NF$\kappa \mathrm{B}$ inhibitor, as a potential therapeutic agent for stroke," International Journal of Molecular Sciences, vol. 18, no. 8, p. 1638, 2017.

[46] J. Geng, W. Liu, Y. Xiong et al., "Andrographolide sulfonate improves Alzheimer-associated phenotypes and mitochondrial dysfunction in APP/PS1 transgenic mice," Biomedicine \& Pharmacotherapy, vol. 97, pp. 1032-1039, 2018.

[47] D. P. Wang, H. Yin, Q. Lin et al., "Andrographolide enhances hippocampal BDNF signaling and suppresses neuronal apoptosis, astroglial activation, neuroinflammation, and spatial memory deficits in a rat model of chronic cerebral hypoperfusion," Naunyn-Schmiedeberg's Archives of Pharmacology, vol. 392, no. 10, pp. 1277-1284, 2019.

[48] B. Salehi, J. Sharifi-Rad, F. Cappellini et al., "The therapeutic potential of anthocyanins: current approaches based on their molecular mechanism of action," Frontiers in Pharmacology, vol. 11, p. 20, 2020.

[49] V. Siokas, A. M. Aloizou, Z. Tsouris et al., "ADORA2A rs5760423 and CYP1A2 rs762551 polymorphisms as risk factors for Parkinson's disease," Journal of Clinical Medicine, vol. 10, 2021.

[50] G. Xu, Y. Li, K. Yoshimoto et al., "2,3,7,8-Tetrachlorodibenzop-dioxin-induced inflammatory activation is mediated by intracellular free calcium in microglial cells," Toxicology, vol. 308, pp. 158-167, 2013.

[51] G. Xu, Y. Li, K. Yoshimoto et al., "2,3,7,8-Tetrachlorodibenzop-dioxin stimulates proliferation of HAPI microglia by affecting the Akt/GSK-3 $\beta /$ cyclin D1 signaling pathway," Toxicology Letters, vol. 224, no. 3, pp. 362-370, 2014.

[52] A. H. Schapira, K. R. Chaudhuri, and P. Jenner, "Non-motor features of Parkinson disease," Nature Reviews Neuroscience, vol. 18, no. 7, pp. 435-450, 2017.

[53] J. Geng, J. Liu, X. Yuan, W. Liu, and W. Guo, "Andrographolide triggers autophagy-mediated inflammation inhibition and attenuates chronic unpredictable mild stress (CUMS)-induced depressive-like behavior in mice," Toxicology and Applied Pharmacology, vol. 379, article 114688, 2019.

[54] J. Geng, W. Liu, J. Gao et al., "Andrographolide alleviates parkinsonism in MPTP-PD mice via targeting mitochondrial fission mediated by dynamin-related protein 1," British Journal of Pharmacology, vol. 176, no. 23, pp. 4574-4591, 2019.
[55] E. J. Yang and K. S. Song, "Andrographolide, a major component of Andrographis paniculata leaves, has the neuroprotective effects on glutamate-induced HT22 cell death," Journal of Functional Foods, vol. 9, pp. 162-172, 2014.

[56] Y. C. Shen, C. F. Chen, and W. F. Chiou, "Andrographolide prevents oxygen radical production by human neutrophils: possible mechanism(s) involved in its anti-inflammatory effect," British Journal of Pharmacology, vol. 135, no. 2, pp. 399-406, 2002.

[57] R. A. Burgos, K. Seguel, M. Perez et al., "Andrographolide inhibits IFN-gamma and IL-2 cytokine production and protects against cell apoptosis," Planta Medica, vol. 71, no. 5, pp. 429-434, 2005.

[58] R. Padureanu, C. V. Albu, R. R. Mititelu et al., "Oxidative stress and inflammation interdependence in multiple sclerosis," Journal of Clinical Medicine, vol. 8, no. 11, p. 1815, 2019.

[59] C. B. Pettinelli and M. F. DE, “Adoptive transfer of experimental allergic encephalomyelitis in SJL/J mice after in vitro activation of lymph node cells by myelin basic protein: requirement for Lyt 1+2- T lymphocytes," Journal of Immunology, vol. 127, pp. 1420-1423, 1981.

[60] M. Sospedra and R. Martin, "Immunology of multiple sclerosis," Annual Review of Immunology, vol. 23, no. 1, pp. 683747,2005

[61] I. I. Ivanov, B. S. McKenzie, L. Zhou et al., "The Orphan Nuclear Receptor ROR $\gamma t$ Directs the Differentiation Program of Proinflammatory IL-17 $7^{+}$T Helper Cells," Cell, vol. 126, no. 6, pp. 1121-1133, 2006.

[62] C. L. Langrish, Y. Chen, W. M. Blumenschein et al., "IL-23 drives a pathogenic $\mathrm{T}$ cell population that induces autoimmune inflammation," The Journal of Experimental Medicine, vol. 201, no. 2, pp. 233-240, 2005

[63] J. S. Tzartos, M. A. Friese, M. J. Craner et al., "Interleukin-17 production in central nervous system-infiltrating $\mathrm{T}$ cells and glial cells is associated with active disease in multiple sclerosis," The American Journal of Pathology, vol. 172, no. 1, pp. 146155,2008

[64] A.-M. Aloizou, V. Siokas, G. Pateraki et al., "Thinking outside the ischemia box: advancements in the use of multiple sclerosis drugs in ischemic stroke," Journal of Clinical Medicine, vol. 10, no. 4, p. 630, 2021.

[65] D. Calina, A. M. Buga, M. Mitroi et al., "The treatment of cognitive, behavioural and motor impairments from brain injury and neurodegenerative diseases through cannabinoid system modulation-evidence from in vivo studies," Journal of Clinical Medicine, vol. 9, no. 8, p. 2395, 2020.

[66] M. Sharifi-Rad, C. Lankatillake, D. A. Dias et al., "Impact of natural compounds on neurodegenerative disorders: from preclinical to pharmacotherapeutics," Journal of Clinical Medicine, vol. 9, 2020.

[67] A.-M. Buga, A. Docea, C. Albu et al., "Molecular and cellular stratagem of brain metastases associated with melanoma," Oncology Letters, vol. 17, no. 5, pp. 4170-4175, 2019.

[68] Y.-C. HOU, Y.-H. WANG, K. LIOU, and Y.-C. SHEN, "Neuroprotective effect of andrographolide against ischemic stroke in rats through reducing iNOS and gp91phox/NOX2 expression," Journal of Chinese Medicine, vol. 21, no. 3-4, 2010.

[69] C. Tapia-Rojas, A. Schüller, C. B. Lindsay et al., “Andrographolide activates the canonical Wnt signalling pathway by a mechanism that implicates the non-ATP competitive 
inhibition of GSK-3 $\beta$ : autoregulation of GSK-3 $\beta$ in vivo," The Biochemical Journal, vol. 466, no. 2, pp. 415-430, 2015.

[70] Y. Liang, M. Li, T. Lu, W. Peng, and J. H. Wu, “Andrographolide promotes neural differentiation of rat adipose tissuederived stromal cells through $\mathrm{Wnt} / \beta$-catenin signaling pathway," BioMed Research International, vol. 2017, Article ID 4210867, 9 pages, 2017.

[71] J. C. Hemphill, S. M. Greenberg, C. S. Anderson et al., "Guidelines for the management of spontaneous intracerebral hemorrhage," Stroke, vol. 46, no. 7, pp. 2032-2060, 2015.

[72] J. B. Kuramatsu, H. B. Huttner, and S. Schwab, "Advances in the management of intracerebral hemorrhage," Journal of Neural Transmission (Vienna), vol. 120, Supplement 1, pp. S35-S41, 2013.

[73] J. Sharifi-Rad, C. F. Rodrigues, F. Sharopov et al., "Diet, lifestyle and cardiovascular diseases: linking pathophysiology to cardioprotective effects of natural bioactive compounds," International Journal of Environmental Research and Public Health, vol. 17, no. 7, 2020.

[74] F. Viana, "Nociceptors: thermal allodynia and thermal pain," in Handbook of Clinical Neurology vol. 156, pp. 103-119, Elsevier, 2018.

[75] F. L. Lin, S. J. Wu, S. C. Lee, and L. T. Ng, "Antioxidant, antioedema and analgesic activities of Andrographis paniculata extracts and their active constituent andrographolide," Phytotherapy Research, vol. 23, no. 7, pp. 958-964, 2009.

[76] A. K. Thakur, S. S. Chatterjee, and V. Kumar, "Adaptogenic potential of andrographolide: an active principle of the king of bitters (Andrographis paniculata)," Journal of Traditional and Complementary Medicine, vol. 5, no. 1, pp. 42-50, 2015.

[77] Z. Yi, S. Ouyang, C. Zhou et al., "Andrographolide inhibits mechanical and thermal hyperalgesia in a rat model of HIVinduced neuropathic pain," Frontiers in Pharmacology, vol. 9, pp. 593-593, 2018.

[78] A. N. Mamelak and D. B. Jacoby, "Targeted delivery of antitumoral therapy to glioma and other malignancies with synthetic chlorotoxin (TM-601)," Expert Opinion on Drug Delivery, vol. 4, no. 2, pp. 175-186, 2007.

[79] M. K. L. Goodenberger and R. B. Jenkins, "Genetics of adult glioma," Cancer Genetics, vol. 205, no. 12, pp. 613-621, 2012.

[80] J. Sharifi-Rad, C. Quispe, J. K. Patra et al., "Paclitaxel: application in modern oncology and nanomedicine-based cancer therapy," Oxidative Medicine and Cellular Longevity, vol. 2021, Article ID 3687700, 2021.

[81] F. Zhao, E. Q. He, L. Wang, and K. Liu, “Anti-tumor activities of andrographolide, a diterpene from Andrographis paniculata, by inducing apoptosis and inhibiting VEGF level," Journal of Asian Natural Products Research, vol. 10, no. 5, pp. 467-473, 2008.

[82] S. H. Yang, S. M. Wang, J. P. Syu et al., "Andrographolide induces apoptosis of C6 glioma cells via the ERK-p53caspase 7-PARP pathway," BioMed Research International, vol. 2014, Article ID 312847, 2014.

[83] C. Bellodi, N. Kopmar, and D. Ruggero, "Deregulation of oncogene-induced senescence and p53 translational control in X-linked dyskeratosis congenita," The EMBO Journal, vol. 29, no. 11, pp. 1865-1876, 2010.

[84] F. Xu, H. Wu, K. Zhang, P. Lv, L. Zheng, and J. Zhao, "Proneurogenic effects of andrographolide on RSC96 Schwann cells in vitro," Molecular Medicine Reports, vol. 14, no. 4, pp. 3573-3580, 2016.
[85] G. Radu, A. D. Bordejevic, V. Buda et al., "Cardiovascular Risk Factors for Different Types of Psychiatric Pathologies. A Correlative Study," Farmacia, vol. 68, no. 5, pp. 835-842, 2020.

[86] L. Trofor, C. D. Radu, C. M. Elisabeta, A. M. Milena, and C. I. Bogdan, "Evaluation of oxidative stress in smoking and nonsmoking patients diagnosed with anxious-depressive disorder," Farmácia, vol. 68, no. 1, pp. 82-89, 2020.

[87] R. Vlad, F. Golu, A. Toma, D. Draganescu, B. Oprea, and B. I. Chiper, "Depression and anxiety in Romanian medical students: prevalence and associations with personality," Farmácia, vol. 68, no. 5, pp. 944-949, 2020.

[88] V. I. R. G. I. L. R. A. D. U. ENĂTESCU, “The efficacy of clonidine in the pharmacological management of alcohol withdrawal syndrome: preliminary results," Farmácia, vol. 68, no. 6, pp. 1069-1074, 2020.

[89] J. Kim, M. Kundu, B. Viollet, and K. L. Guan, "AMPK and mTOR regulate autophagy through direct phosphorylation of Ulk1," Nature Cell Biology, vol. 13, no. 2, pp. 132-141, 2011.

[90] L. Z. Xu, D. F. Xu, Y. Han et al., "BDNF-GSK-3 $\beta$ - $\beta$-catenin pathway in the $\mathrm{mPFC}$ is involved in antidepressant-like effects of Morinda officinalis oligosaccharides in rats," The International Journal of Neuropsychopharmacology, vol. 20, no. 1, pp. 83-93, 2017.

[91] C. A. Bradley, S. Peineau, C. Taghibiglou et al., "A pivotal role of GSK-3 in synaptic plasticity," Frontiers in Molecular Neuroscience, vol. 5, 2012.

[92] N. C. Inestrosa and E. Arenas, "Emerging roles of Wnts in the adult nervous system," Nature Reviews. Neuroscience, vol. 11, no. 2, pp. 77-86, 2010.

[93] S. Peineau, C. Taghibiglou, C. Bradley et al., "LTP inhibits LTD in the hippocampus via regulation of GSK3 $\beta$," Neuron, vol. 53, no. 5, pp. 703-717, 2007.

[94] W. R. Gibb and A. J. Lees, “Anatomy, pigmentation, ventral and dorsal subpopulations of the substantia nigra, and differential cell death in Parkinson's disease," Journal of Neurology, Neurosurgery, and Psychiatry, vol. 54, no. 5, pp. 388-396, 1991.

[95] L. V. Kalia and A. E. Lang, "Parkinson's disease," The Lancet, vol. 386, no. 9996, pp. 896-912, 2015.

[96] J. E. Merrill, S. R. Strom, G. W. Ellison, and L. W. Myers, "In vitro study of mediators of inflammation in multiple sclerosis," Journal of Clinical Immunology, vol. 9, no. 2, pp. 84-96, 1989.

[97] T. L. Yen, W. H. Hsu, S. K. Huang et al., "A novel bioactivity of andrographolide from Andrographis paniculata on cerebral ischemia/reperfusion-induced brain injury through induction of cerebral endothelial cell apoptosis," Pharmaceutical Biology, vol. 51, no. 9, pp. 1150-1157, 2013.

[98] A. I. Qureshi, A. D. Mendelow, and D. F. Hanley, "Intracerebral haemorrhage," Lancet, vol. 373, no. 9675, pp. 16321644, 2009. 